\title{
GROWTH FACTORS OF INDUSTRIAL-SECTOR VALUE ADDED IN 2015
}

\section{E.Astafieva}

The results of decomposition of output growth suggest that in 2015 the main factor inputs increased while the gross value added (GVA) of industrial production dropped. Capital inputs play a dominant part in the structure of main factor inputs in industry. According to preliminary estimates, the total factor productivity (TFP) of the main industrial types of economic activity declined at faster rates than in the prior period.

Decomposition of economic growth is one of the approaches towards studying the causes of differentiation of growth rates of various types of economic activity. The approach is based on the assumption that output growth rates come from the sum of three summands according to estimates of the differential form of the production function. The first two summands correspond to the effect of the dynamics of extensive components of growth, namely main factor inputs such as labour and capital. The estimation method assumes that factor inputs are the product of factor reserves (the number of employed persons and the volumes of fixed assets) by the rate of their utilization (hours actually worked per worker and the production capacity utilization rate). The third summand corresponds to the total factor productivity (TFP) and is considered as the characteristics of intensive components of growth. This summand constitutes the remainder not explained by the main factors. Such estimate of the total factor productivity reflects not only changes in "technological" components but also exogenous shocks, the effect of enhancing the effectiveness of production engineering, the quality of management, as well as changes in demand and price environment.

The data released by Russia's Federal State Statistics Service known as Rosstat show that in 2015 the extractive sector saw its gross value added (GVA) increase $1.1 \%$ from 2014, whereas there was a decline of $1.7 \%$ in the production and distribution of electric power, gas and water, as well as of $5.5 \%$ in manufacturing sectors. When compared with the previous period, all the industrial types of economic activity saw their GVA growth rates slow down to 1.0 p.p. in the extractive sector, 1.4 p.p. in the production and distribution of electric power, gas and water, and 6.5 p.p. in manufacturing.

In 2015, enterprises engaged in the extraction of commercial minerals were alone in industry in terms of showing positive growth rates of the value added. The decomposition of GVA growth rates of this type of economic activity in 2015 differs little from what the manufacturing sector demonstrated in the past few years. The results obtained (Table 1) show that the growth rates of the main factor inputs are way ahead of the value added growth rates in extractive industries, which is determined by simultaneous growth of both extensive components. Capital inputs are (as before) dominant in the structure of main factor inputs of enterprises engaged in the extraction of commercial minerals: total growth rates of the extensive components are determined more than $90 \%$ by the increase in the volumes of fixed assets. Growth rates of labour inputs in this type of economic activ- 
DECOMPOSITION OF GROWTH RATES IN THE INDUSTRIAL SECTOR VALUE ADDED IN 2014-2015*

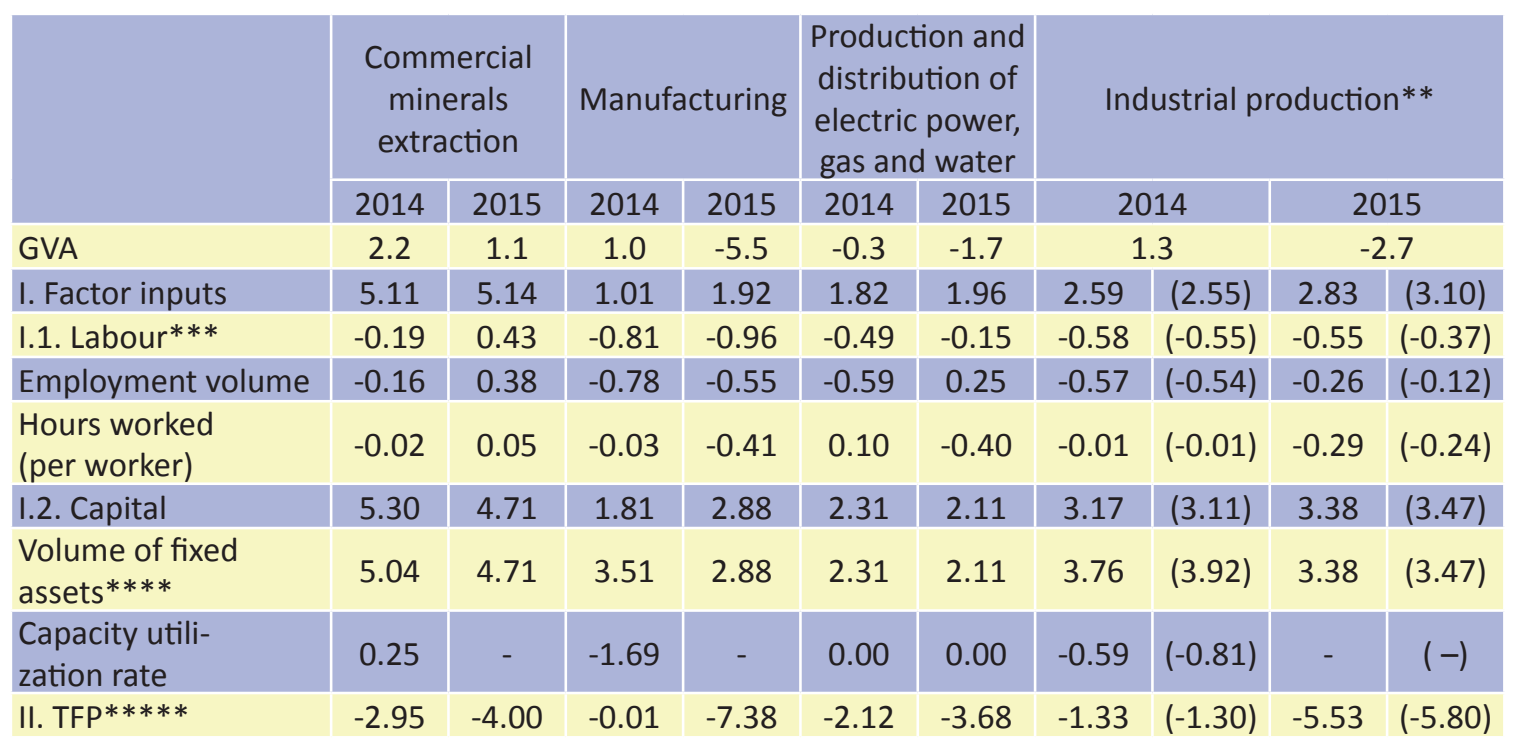

* Preliminary estimate is presented for 2015.

The estimates disagree with earlier estimates because Rosstat adjusted production indices.

** Industrial production is estimated by aggregating initial estimates by type of economic activity (the figures in brackets stand for the results of decomposition obtained by pooling estimates by type of economic activity).

*** The preliminary estimate of growth rates of the number of employed persons in the industrial sector comes from the data for the number of jobs substituted in 2015 on the assumption of invariable relationship between the number of employed persons by type of economic activity and the number of substituted jobs.

**** The preliminary estimate of growth of the physical volume of fixed assets in 2015 comes from the assumption of invariable fixed assets retirement rate and invariable share of investment in their replacement.

***** The 2015 TFP estimate in the extractive sector, manufacturing sector as well as across industry is biased due to a lack of the data required for estimating changes in the capacity utilization rate of enterprises engaged in these types of economic activity.

ity are much slower. The increase in the labour inputs is determined by the number of employed persons growing simultaneously with their hours worked, in which case the labour reserves grow faster than their utilization rate.

At the 2015 year-end, enterprises engaged in the extraction of commercial minerals were characterized by contraction of the total factor productivity. As noted above, the TFP estimate is the remainder not explained by the main factors. In particular, using cost parameters of output and capital may bias the TFP estimate due to the variance of price dynamics of output and fixed assets. Compared to other industrial production, the TFP dynamics of the extractive sector depends to a greater extent on price movements in global commercial minerals markets. The econometric estimation ${ }^{1}$ of the relationship between TFP growth rates and growth rates of global oil prices reveals two TFP components, namely the market component (which is governed by price movements in global commercial minerals markets) and the "ultimate remainder". Note that deriving from the extractive-sector's TFP a component governed by movements in crude oil prices does not alter qualitatively the conclusions about total productivity dynamics: the "ultimate remainder" also

1 The market-related component is derived from TFP by assessing the regression of TFP growth rates on the growth rates of crude global prices using the data for the period between 1993 and 2015. 
demonstrates negative growth rates. However, the contraction of the "ultimate remainder" is less intensive than that of TFP.

Like in previous years, changes in the manufacturing output dynamics are most conspicuous in economy, with the fastest in industry decline rates of the value added in 2015. Decomposition of the GVA decline in the manufacturing sector is characterized by mixed dynamics of output and of the main factor inputs: output declines with an increase in extensive components. Positive growth rates of the main factor inputs for this type of economic activity are fully determined by the increase of capital inputs, although the fixed assets of manufacturing enterprises are down compared to prior periods. As before, the labour inputs of manufacturing enterprises decreased in volume in 2015, weakening the contribution of the main factor inputs to GVA growth rates. The labour inputs decreased because the number of employed persons reduced simultaneously with their worked hours, whose contribution to GVA growth rates of this type of economic activity is nearly equal.

According to preliminary data (excluding changes in the production capacity utilization rate), manufacturing enterprises see TFP fall, with the total factor productivity declining faster than the value added of this type of economic activity. Note that in 2015 the TFP dynamics in manufacturing sectors was characterized by a considerable decline, this type of economic activity facing the slowest in industry TFP decline rates.

Enterprises engaged in the production and distribution of electric power, gas and water show negative growth rates of the value added too. The results of decomposition reveal that the decrease of GVA volumes of this type of economic activity is fully governed by the decrease of TFP, while the main factor inputs are on the raise. Like in the manufacturing sector, the structure of extensive factors in the production and distribution of electric power, gas and water is characterized by capital inputs increasing and labour inputs decreasing. The increase of capital inputs of this type of economic activity is driven by growth of fixed assets. The decrease of the labour inputs of enterprises engaged in the production and distribution of electric power, gas and water is due to a reduction of hours worked with much less increase in the number of employed persons.

The results of the estimates for the aggregated data by type of economic activity suggest that overall growth rates of the industrial-sector value added in 2015 stood at 4.0 p.p. below (down 2.7\%) the 2014 level.

According to the preliminary results of decomposition (no data for the capacity utilization rate are available), 2015 saw GVA of industrial production reduce while the main factor inputs were on the rise. Despite fixed assets' growth rates declining, capital inputs remained the domi-

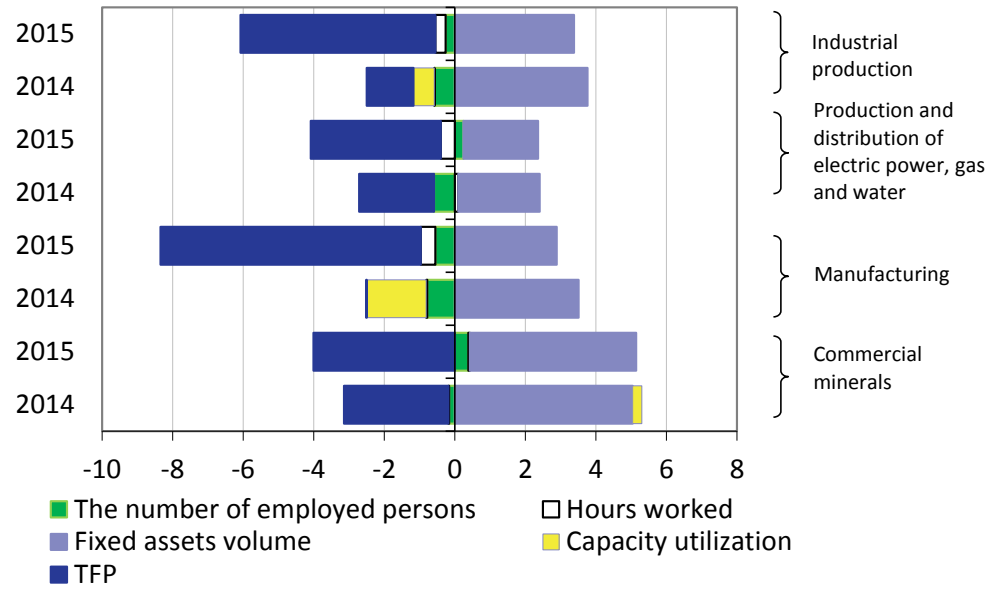

Fig. 1. The growth structure of industrial-sector gross value added in 2014-2015 
nant growth driver of the value added in the structure of extensive factors. The labour inputs of industrial enterprises declined in 2015, resulting in the main factor inputs contributing less to GVA growth rates. Like in prior periods, the decline of labour inputs is determined by negative growth rates in the number of employed persons and their hours worked. The 2015 TFP growth rates of the industrial production are negative too, and the total factor productivity declined much deeper than in prior periods. A slightly different contribution of the productivity to GVA growth rates of industrial production comes from deriving from TFP a component representing redistribution of the value added, labour inputs and capital inputs by type of economic activity. The increase of the differences in the TFP estimates obtained using the aggregated data and sectoring are indicative of intensified process of redistribution of resources between industrial types of economic activity in 2015 compared with the earlier period.

In 2015, GVA growth rates in industry differed by sector: in terms of volume, the extractive sector saw the value added increase, whereas the manufacturing sector and the production and distribution of electric power, gas and water were on the slide. At the same time, what is common for all of them is that GVA growth rates are slower than in the prior period.

The results of decomposition reveal a few facts that are common for all the types of economic activity. First, the main factor inputs show positive growth rates in the key industrial sectors. At the same time, growth rates of extensive factors are either way ahead of GVA growth rates or they vary in dynamics. Second, capital inputs is the dominant component of the structure of main factor inputs. Their growth is governed by increased volumes of fixed assets whose growth rates have slowed down in the past few years. Third, the changes in labour inputs of industrial sectors are largely outperformed by the changes in capital inputs. In other words, extensive factors in industry currently increase through capital build-up.

According to preliminary estimates (no data for the capacity utilization rate are available), the total factor productivity of industrial production saw negative growth rates in 2015. TFP growth rates by type of economic activity were negative too. Additionally, the TFP of all the industrial types of economic activity saw faster decline rates compared to the prior period. 